\title{
Trends in overweight by socio-economic status in Vietnam: 1992 to 2002
}

\author{
Minh Duc Nguyen ${ }^{1}$, Shirley AA Beresford ${ }^{2,3}$ and Adam Drewnowski ${ }^{2,3, *}$ \\ ${ }^{1}$ National Institute of Nutrition of Vietnam, Hanoi, Vietnam: ${ }^{2}$ Nutritional Sciences Program, School of Public Health \\ and Community Medicine, University of Washington, Seattle, WA, USA: ${ }^{3}$ Center for Public Health Nutrition, 305 \\ Raitt Hall, Box 353410, University of Washington, Seattle, WA 98195-3410, USA
}

Submitted 9 August 2005: Accepted 3 August 2006

\begin{abstract}
Objective: To explore socio-economic factors associated with rising rates of overweight among Vietnamese adults.

Design: The study was based on three national surveys of socio-economic factors and health conducted over a 10-year period. The studies were: the Vietnamese Living Standard Survey 1992-1993 (11982 participants); the Vietnamese Living Standard Survey 1997-1998 (15975 participants); and the Vietnamese National Health Survey 2001-2002 (94656 participants).

Subjects: Male and female adults $>18$ years old were stratified by gender, age group, area of residence, occupation, education and relative food expenditures. Overweight was defined using body mass index (BMI) $\geq 25 \mathrm{~kg} \mathrm{~m}^{-2}$.

Results: Overweight rates in Vietnam more than doubled between 1992 and 2002 (from 2.0 to 5.7\%). Significant increases were observed for men and women, in urban and rural areas, and for all age groups. In univariate analyses, both age and higher socio-economic status were associated with higher rates of overweight. Using the most recent survey, urban populations were more likely to be overweight than rural ones (odds ratio $(\mathrm{OR})=1.79$ ), white-collar workers were more likely to be overweight than manual labourers $(\mathrm{OR}=1.95)$ and persons in the top level of food expenditures were more likely to be overweight than persons in the bottom level $(\mathrm{OR}=4.96)$ after adjustment for other factors. Education was inversely associated with overweight after adjusting for covariates.

Conclusion: Economic growth and improved standard of living are associated with higher rates of overweight in nations in early stages of economic development. In Vietnam, higher rates of overweight were observed among the higher income and occupation groups.
\end{abstract}

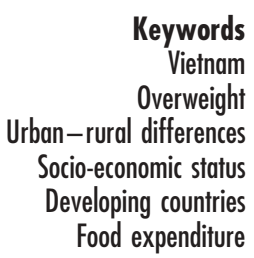

Vietnam

Overweight Socio-econal differences Developing countries Food expenditure
Economic development brings about profound changes in lifestyles and diet composition ${ }^{1,2}$. As nations industrialise and populations become more urban, the traditional plantbased diets are replaced by diets with more animal products and a higher proportion of added sugars and fats ${ }^{3-5}$. This nutrition transition in the developing world has been associated with rapidly growing rates of overweight ${ }^{6,7}$. However, the socio-economic determinants of overweight in developing countries are not always clear. Whereas some studies suggest that overweight in low-income nations is more common among groups with higher socio-economic status (SES) ${ }^{8-10}$, other studies suggest that overweight is increasing faster among the poor ${ }^{7,11,12}$.

The economic growth of Vietnam, linked to the Doi Moi economic reforms beginning in $1986^{13}$, has led to urbanisation, higher incomes ${ }^{14,15}$ and major shifts in diet composition, especially among the more affluent urban dwellers ${ }^{16}$. With a Gross National Product (GNP) estimated at \$US 430 per capita in $2002^{17}$, Vietnam faces the dual challenge of continuing undernutrition and rising rates of overweight, especially among women.

The present analyses of cross-sectional surveys focused on social and economic variables associated with overweight in the adult Vietnamese population. The three surveys were conducted in Vietnam over a 10-year period (1992-2002) with support from the World Bank and the Swedish International Development Agency (SIDA) ${ }^{15,18,19}$. Factors selected for this study were gender, age, area of residence (urban/rural), education, occupation and a scale measure of relative food expenditures. The goal was to track overweight rates over the 10-year period as they affected men and women, urban and rural dwellers, and diverse SES groups. One hypothesis, suggested by past research, was that stages of economic development have more of an impact on the body weight of women than the body weight of $\operatorname{men}^{20-22}$. 


\section{Methods}

\section{Survey design}

The two Vietnamese Living Standard Surveys were multipurpose surveys that focused primarily on general statistics of economic development ${ }^{15,18}$. They were conducted in 1992-1993 (VLSS 1992-93) ${ }^{18}$ and 19971998 (VLSS $1997-98)^{15}$ by the General Office of Statistics of Vietnam with financial support provided by the World Bank. The Vietnamese National Health Survey was conducted in 2001-2002 (VNHS 2001-02) by the Ministry of Health of Vietnam with support from the World Bank and SIDA $^{19}$. The key findings of these nationally representative surveys have been published before ${ }^{15,18,19}$.

The VLSS were based on multi-stage random sampling methods, using the 1989 census. Sample frames were stratified into rural and urban areas and then households were selected randomly. Data were collected for each member of the targeted households, including children. The VLSS 1997-98 collected data from the same households as the VLSS 1992-93, plus an additional 1200 drawn from the 1995 Multi-Purpose Household Survey. The VLSS 1992-93 was based on 4800 households, and the VLSS 1997-98 was based on 6000 households. The total samples included 23839 individuals in VLSS 1992-93 and 28509 in VLSS 1997-98.

The VNHS 2001-02 sample frame was based on the 1999 census. Thirty-six thousand households were randomly selected from clusters derived from the 61 provinces and stratified by urban and rural areas. Data were obtained for each member of the household, for an approximate total of 158000 individuals.

\section{Key variables and statistical analyses}

Height and weight were measured for all participants and body mass index (BMI, $\mathrm{kg} \mathrm{m}^{-2}$ ) values were calculated. Following the definition of the World Health Organization (WHO) ${ }^{5}$, overweight was defined as $\mathrm{BMI} \geq 25 \mathrm{~kg} \mathrm{~m}^{-2}$. Area of residence (urban/rural) was ascertained from the sampling frame. Data on gender, age, education, occupation and food expenditure were obtained through self-report. Only subjects over 19 years of age were included in this study. Age was categorised into three groups: $19-30$ years; 31-50 years; and >51 years. Education was categorised into six groups according the number of years of education: illiterate (0 year); < primary school ( $<5$ years); primary school (5 years); secondary school (9 years); high school (12 years); $>$ high school ( $>12$ years). Occupation was categorised into three groups: white collar; manual labour; and other. Food expenditure, a proxy for income, was categorised into five expenditure levels $(1=$ lowest, $5=$ highest $)$. Participants selected the most appropriate level from the five choices (values were in Vietnamese Dong).

Statistical analyses were conducted with SPSS, version 12.0 (SPSS Inc.). Simple differences in overweight rates as a function of gender, area of residence and age group were tested using chi-square statistics. Multiple logistic regression analysis was used to test the association between SES factors, independent of other factors in the analyses, and the prevalence of overweight within the VNHS 2001-02 dataset. Age standardisation used the direct method ${ }^{23}$. Stata version 9 (StataCorp) was used to calculate odds ratios (OR).

\section{Results}

The three survey samples reflected the changing demographics of Vietnam during the period 1992 to 2002. Table 1 shows demographic data for all survey participants. In all three surveys, $\sim 54 \%$ of participants were female. Over the 10 -year period, the $31-50$ years age group increased in size and there was a decline in the number of 19-30-year-olds. Between 1992 and 2002, the proportion of urban dwellers in the three survey samples rose from 23.1 to $35.1 \%$. Illiteracy rates declined and the proportion of adults with high school education or above increased from 13.6 to $20.3 \%$. The proportion of white-collar workers rose from 17.5 to $28.0 \%$.

Table 2 shows the rising prevalence of overweight as a function of gender and age group. Women were more likely to be overweight than were men, an effect that was stronger among the older adults. There was a sharp increase in overweight prevalence between 1992 and 2002, in parallel with economic development. In 1992, the crude prevalence of overweight was $1.1 \%$ for men and 2.8\% for women (age-standardised: 1.2 and 3.0\%, respectively). By 2002, the crude prevalence had risen to $4.5 \%$ for men and 6.6\% for women (age-standardised: 4.4 and $6.6 \%$, respectively). These effects were significant after adjusting for unequal distribution of participants by age in the three surveys.

Table 3 shows the rising prevalence rates of overweight as a function of area of residence for each age group. In 1992, the prevalence of overweight was $1.2 \%$ in rural areas and $4.8 \%$ in urban areas. By 2002, overweight rates in rural areas tripled to $3.5 \%$, whereas overweight rates in urban areas doubled to $9.6 \%$. Although the prevalence remained highest for the urban groups, rural populations showed the sharpest rate of increase. The differences in overweight prevalence between urban and rural dwellers were most pronounced for older adults.

Figure 1 shows the relationship between overweight prevalence and food expenditure in the three surveys, for men and women. In this survey, food expenditure served as a proxy measure of income. Higher food expenditure (level 5) was associated with higher overweight prevalence. As the prevalence of overweight increased between 1992 and 2002, higher rates were progressively observed among all SES groups. Consistent with past observations, the trend to increased overweight prevalence was more 
Table 1 A summary of participant data in three Vietnamese national surveys

\begin{tabular}{|c|c|c|c|c|c|c|}
\hline \multirow[b]{3}{*}{ Data } & \multicolumn{6}{|c|}{ Participants in surveys } \\
\hline & \multicolumn{2}{|c|}{$\begin{array}{c}\text { VLSS } \\
1992-93\end{array}$} & \multicolumn{2}{|c|}{$\begin{array}{c}\text { VLSS } \\
1997-98\end{array}$} & \multicolumn{2}{|c|}{$\begin{array}{c}\text { VNHS } \\
2001-02\end{array}$} \\
\hline & $\%$ & $n$ & $\%$ & $n$ & $\%$ & $n$ \\
\hline \multicolumn{7}{|l|}{ Gender } \\
\hline Male & 45.3 & 5425 & 45.7 & 7307 & 46.8 & 44254 \\
\hline Female & 54.7 & 6557 & 54.3 & 8668 & 53.2 & 50402 \\
\hline Total & 100.0 & 11982 & 100.0 & 15975 & 100.0 & 94656 \\
\hline \multicolumn{7}{|l|}{ Age group (years) } \\
\hline $19-30$ & 35.5 & 4250 & 29.9 & 4774 & 28.8 & 27274 \\
\hline $31-50$ & 38.7 & 4640 & 42.1 & 6728 & 45.7 & 43238 \\
\hline $51+$ & 25.8 & 3092 & 28.0 & 4473 & 25.5 & 24144 \\
\hline Total & 100.0 & 11982 & 100.0 & 15975 & 100.0 & 94656 \\
\hline \multicolumn{7}{|c|}{ 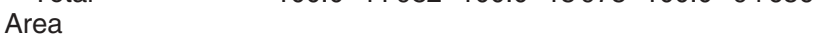 } \\
\hline Rural & 76.9 & 9212 & 68.9 & 11010 & 64.9 & 61421 \\
\hline Urban & 23.1 & 2769 & 31.1 & 4961 & 35.1 & 33235 \\
\hline Total & 100.0 & 11981 & 100.0 & 15971 & 100.0 & 94656 \\
\hline \multicolumn{7}{|c|}{ ש } \\
\hline Illiterate & 13.6 & 1628 & 10.9 & 1743 & 8.2 & 7757 \\
\hline Literate & 22.7 & 2714 & 22.1 & 3524 & 18.3 & 17301 \\
\hline Prima & 26.4 & 3164 & 26.7 & 4255 & 25.6 & 24189 \\
\hline Secondary school & 23.8 & 2846 & 25.4 & 4044 & 27.6 & 26159 \\
\hline High school & 7.7 & 923 & 10.7 & 1701 & 10.7 & 10145 \\
\hline Above high school & 5.9 & 703 & 4.3 & 679 & 9.6 & 9067 \\
\hline Total & 100.0 & 11978 & 100.0 & 15946 & 100.0 & 94618 \\
\hline \multicolumn{7}{|l|}{ Occupation } \\
\hline White collar & 17.5 & 1831 & 21.0 & 2940 & 28.0 & 22316 \\
\hline Manual labour & 82.3 & 8587 & 78.9 & 11024 & 71.5 & 56932 \\
\hline Others & 0.2 & 20 & 0.1 & 10 & 0.5 & 422 \\
\hline Total & 100.0 & 10438 & 100.0 & 13974 & 100.0 & 79670 \\
\hline \multicolumn{7}{|c|}{ Food expenditure level } \\
\hline Level 1 & 16.8 & 2018 & 15.0 & 2398 & 17.0 & 16057 \\
\hline Level 2 & 18.2 & 2176 & 16.5 & 2640 & 17.8 & 16804 \\
\hline Level 3 & 19.8 & 2377 & 19.0 & 3028 & 19.6 & 18537 \\
\hline Level 4 & 21.6 & 2584 & 22.2 & 3544 & 22.2 & 20972 \\
\hline Level 5 & 23.6 & 2826 & 27.3 & 4361 & 23.4 & 22120 \\
\hline Total & 100.0 & 11981 & 100.0 & 15971 & 100.0 & 94,490 \\
\hline
\end{tabular}

VLSS 1992-93-Vietnamese Living Standard Survey 1992-1993; VLSS 1997-98-Vietnamese Living Standard Survey 1997-1998; VNHS 200102-Vietnamese National Health Survey 2001-2002.

pronounced for women than for men, especially among those with lower SES.

Figure 2 shows the relationship between overweight prevalence and food expenditure, in rural and urban areas. In 1992, the prevalence of overweight in rural areas was very low, regardless of income. However, overweight rates in both rural and urban areas increased sharply between 1992 and 2002. By 2002, the prevalence of overweight in urban areas was spreading to the lower SES groups. In contrast, in rural areas only participants in the top level of food expenditures had overweight prevalence in excess of $4 \%$ by 2002.

Table 4 shows the influence of SES factors on overweight prevalence in the VHNS 2001-02 data, as determined by a regression model before and after adjusting for covariates. There was a strong gender effect, with women more likely to be overweight than men, adjusting for age, area, education, occupation and food expenditure (adjusted $\mathrm{OR}=1.31)$. Older adults $(>51$ years) were more likely to be overweight than were
Table 2 Percentage of overweight (body mass index $\geq 25 \mathrm{~kg} \mathrm{~m}^{-2}$ ) by gender and age group. Data from VLSS 1992-93, VLSS 1997-98 and VNHS 2001-02

\begin{tabular}{|c|c|c|c|c|c|}
\hline \multirow[b]{3}{*}{ Survey } & \multirow[b]{3}{*}{ Age group (years) } & \multicolumn{4}{|c|}{$\begin{array}{l}\text { Percentage of overweight } \\
\text { and number of cases }\end{array}$} \\
\hline & & \multicolumn{2}{|c|}{ Men } & \multicolumn{2}{|c|}{ Women } \\
\hline & & $\%$ & Cases & $\%$ & Cases \\
\hline \multirow[t]{3}{*}{ VLSS 1992-93 } & $19-30$ & 0.4 & 8 & 0.9 & 21 \\
\hline & $31-50$ & 1.3 & 27 & 4.1 & 103 \\
\hline & $51+$ & 1.8 & 24 & 3.5 & 60 \\
\hline \multirow[t]{2}{*}{ All age groups } & Crude total & 1.1 & 59 & 2.8 & 184 \\
\hline & Age-standardised & 1.2 & & 3.0 & \\
\hline \multirow[t]{3}{*}{ VLSS 1997-98 } & $19-30$ & 1.0 & 24 & 1.4 & 34 \\
\hline & $31-50$ & 4.1 & 126 & 7.1 & 260 \\
\hline & $51+$ & 3.6 & 69 & 7.3 & 189 \\
\hline \multirow[t]{2}{*}{ All age groups } & Crude total & 3.0 & 219 & 5.6 & 483 \\
\hline & Age-standardised & 3.1 & & 5.5 & \\
\hline \multirow[t]{3}{*}{ VNHS 2001-02 } & $19-30$ & 2.0 & 232 & 2.3 & 310 \\
\hline & $31-50$ & 5.6 & 1086 & 8.0 & 1762 \\
\hline & $51+$ & 5.1 & 496 & 8.8 & 1127 \\
\hline \multirow[t]{2}{*}{ All age groups } & Crude total & 4.5 & 1814 & 6.6 & 3199 \\
\hline & Age-standardised & 4.4 & & 6.6 & \\
\hline
\end{tabular}

VLSS 1992-93-Vietnamese Living Standard Survey 1992-1993; VLSS 1997-98-Vietnamese Living Standard Survey 1997-1998; VNHS 200102-Vietnamese National Health Survey 2001-2002.

younger adults (adjusted $\mathrm{OR}=3.37$ ). Urban dwellers were more likely to be overweight than rural dwellers (adjusted $\mathrm{OR}=1.79$ ). White-collar workers were more likely to be overweight than manual labourers (adjusted $\mathrm{OR}=1.95$ ). Higher food expenditure, a proxy for income, was also associated with higher rates of overweight.

In the unadjusted model, higher education was associated with higher overweight prevalence. However, education levels in Vietnam are strongly correlated with urban residence and white-collar employment. After adjusting for the other variables, the relationship between

Table 3 Percentage of overweight (body mass index $\geq 25 \mathrm{~kg} \mathrm{~m}^{-2}$ ) by area and age group. Data from VLSS 1992-93 VLSS 1997-98 and VNHS 2001-02

\begin{tabular}{|c|c|c|c|c|c|}
\hline \multirow[b]{3}{*}{ Survey } & \multirow[b]{3}{*}{ Age group (years) } & \multicolumn{4}{|c|}{$\begin{array}{l}\text { Percentage of overweight } \\
\text { and number of cases }\end{array}$} \\
\hline & & \multicolumn{2}{|c|}{ Rural } & \multicolumn{2}{|c|}{ Urban } \\
\hline & & $\%$ & Cases & $\%$ & Cases \\
\hline \multirow[t]{4}{*}{ VLSS 1992-93 } & $19-30$ & 0.5 & 18 & 1.1 & 11 \\
\hline & $31-50$ & 1.6 & 56 & 6.7 & 74 \\
\hline & $51+$ & 1.5 & 36 & 7.0 & 48 \\
\hline & Total & 1.2 & 110 & 4.8 & 133 \\
\hline \multirow[t]{4}{*}{ VLSS 1997-98 } & $19-30$ & 0.6 & 20 & 2.6 & 38 \\
\hline & $31-50$ & 3.1 & 142 & 11.5 & 243 \\
\hline & $51+$ & 2.9 & 89 & 12.1 & 169 \\
\hline & Total & 2.3 & 251 & 9.1 & 450 \\
\hline \multirow[t]{4}{*}{ VNHS 2001-02 } & $19-30$ & 1.6 & 262 & 3.3 & 280 \\
\hline & $31-50$ & 4.3 & 1,123 & 11.5 & 1275 \\
\hline & $51+$ & 4.3 & 631 & 13.0 & 992 \\
\hline & Total & 3.5 & 2,016 & 9.6 & 2,997 \\
\hline
\end{tabular}

VLSS 1992-93-Vietnamese Living Standard Survey 1992-1993; VLSS 1997-98-Vietnamese Living Standard Survey 1997-1998; VNHS 2001-02 -Vietnamese National Health Survey 2001-2002. 

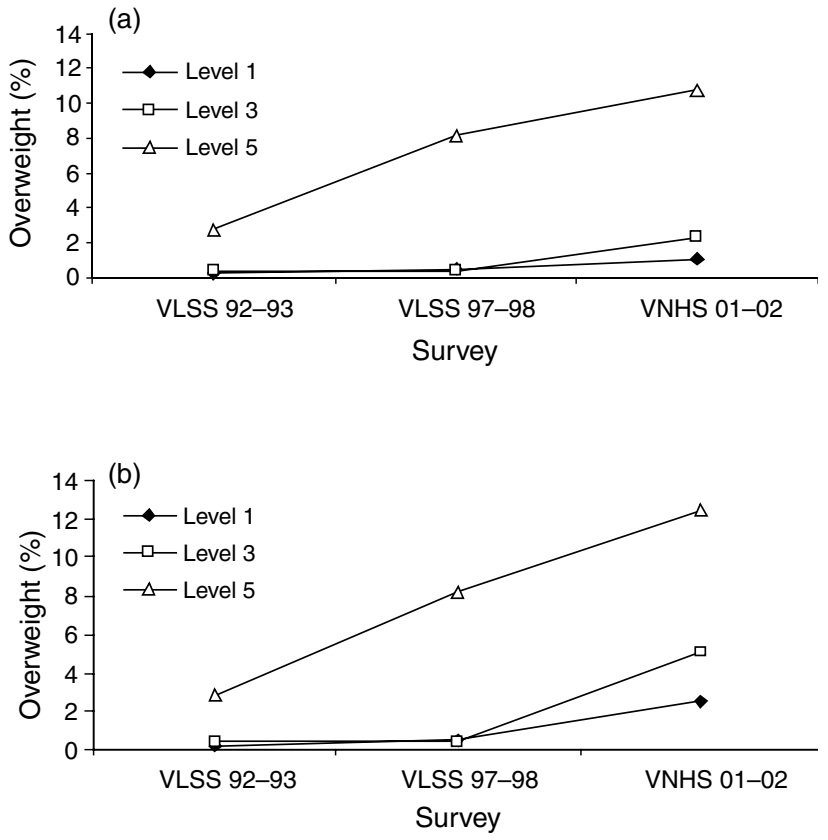

Fig. 1 Percentage of overweight (body mass index $\geq 25 \mathrm{~kg} \mathrm{~m}^{-2}$ ) in the first, third and fifth food expenditure levels for men (a) and women (b). Data from the Vietnamese Living Standard Survey 1992-1993 (VLSS 1992-93), the Vietnamese Living Standard Survey 1997-1998 (VLSS 1997-98) and the Vietnamese National Health Survey 2001-2002 (VNHS 2001-02)

overweight and higher educational attainment became inverse, with an adjusted OR of 0.62 .

\section{Discussion}

The prevalence of overweight in Vietnam more than doubled between 1992 and 2002 (from 2.0 to 5.7\%). Significant increases were observed for men and women, in all age groups, and in both urban and rural areas. While the prevalence of overweight was substantially below that observed in middle-income developing nations, let alone the industrialised world, the rapid rate of increase is troublesome $^{12}$. It would appear from this and other studies $^{6,9,24}$ that the rising rates of overweight are one undesirable consequence of economic development.

In Vietnam, higher rates of overweight were observed among the more affluent urban residents. In a classic study, Sobal and Stunkard reviewed obesity rates in 130 populations in developed countries and 14 populations in developing countries in relation to SES ${ }^{12}$. They concluded that in low-income nations it was the more affluent who were obese, whereas in higher-income nations, less wealthy people were heavier ${ }^{12}$. Other studies demonstrated that the socio-economic gradient was steeper and more consistent for women than for men ${ }^{6,24,25}$. Most recently, Monteiro et al. ${ }^{20}$ reported that in countries with per capita GNP less than \$US 2500, female overweight disproportionately affected the more affluent, whereas the reverse was true in countries with per capita GNP greater than \$US 2500.
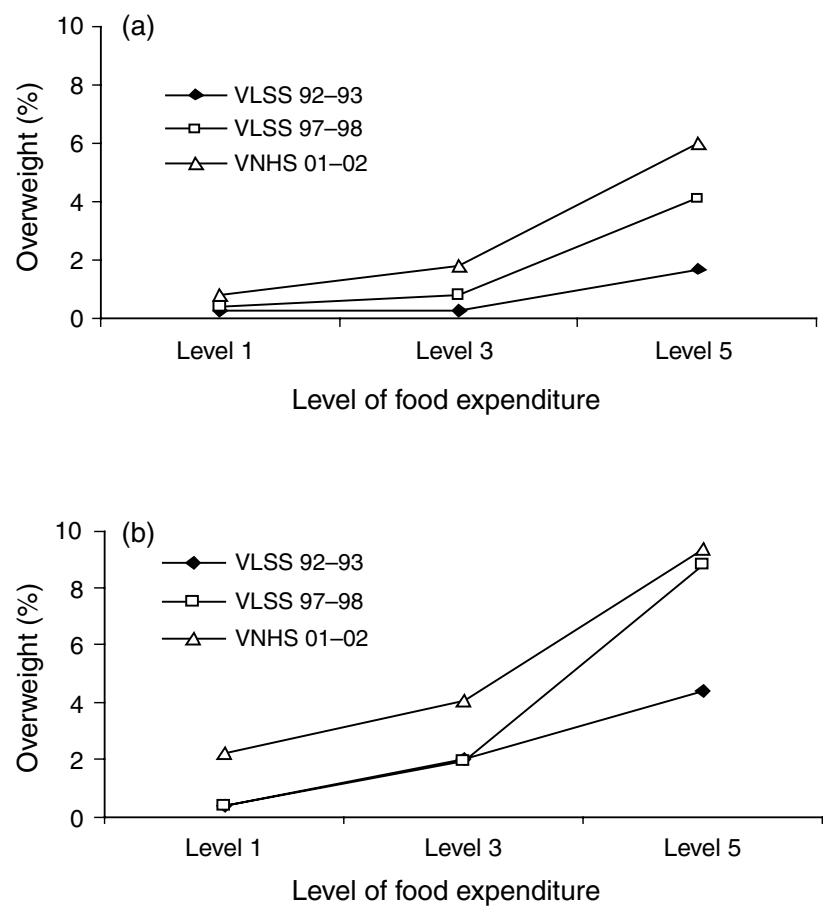

Fig. 2 Percentage of overweight (body mass index $\geq 25 \mathrm{~kg} \mathrm{~m}^{-2}$ ) by food expenditure level in rural (a) and urban (b) areas. Data from the Vietnamese Living Standard Survey 1992-1993 (VLSS 1992-93), the Vietnamese Living Standard Survey 1997-1998 (VLSS 1997-98) and the Vietnamese National Health Survey 2001-2002 (VNHS 2001-02)

Higher rates of overweight in Vietnam were positively linked to a number of SES indices. High occupation status in developing countries is associated with higher prevalence of overweight and obesity ${ }^{9,24,26}$. In Vietnam, white-collar workers were more likely to be overweight than manual labourers. Higher overweight prevalence among white-collar workers is consistent with parallel observations in other low-income developing countries $7,12,25,27$. For example, in Ghana white-collar jobs were also associated with overweight ${ }^{21}$. Urban dwellers were more likely to be overweight than rural dwellers, after adjusting for other factors. These data are also consistent with numerous other studies, notably those conducted in Brazil ${ }^{3,28}$.

In developing nations, higher education levels are associated with overweight ${ }^{9,24}$. In developed nations the reverse is true $\mathrm{e}^{29-31}$. In Vietnam, education is highly correlated with white-collar profession, urban residence and higher income. When factors are held constant, education appeared to have a protective effect on overweight, making this finding in Vietnam consistent with what is found in developed nations. While not entirely collinear, education, urban residence and white-collar employment were correlated as is the case in nations at this level of development.

A country in early stages of economic development, Vietnam had a per capita GNP of \$US 430 in $2002^{17}$. 
Table 4 Socio-economic factors and overweight in the VNHS 2001-02: a regression model

\begin{tabular}{|c|c|c|c|}
\hline \multirow[b]{2}{*}{ Variable } & \multirow[b]{2}{*}{$n$} & \multicolumn{2}{|c|}{ Overweight } \\
\hline & & Unadjusted OR $(95 \% \mathrm{Cl})$ & Adjusted OR $(95 \% \mathrm{Cl}) \dagger$ \\
\hline \multicolumn{4}{|l|}{ Gender } \\
\hline Male & 44254 & 1.00 (ref) & 1.00 (ref) \\
\hline Female & 50402 & $1.53^{*}(1.44-1.62)$ & $1.31 *(1.21-1.41)$ \\
\hline \multicolumn{4}{|l|}{ Age group (years) } \\
\hline $19-30$ & 27274 & 1.00 (ref) & 1.00 (ref) \\
\hline $31-50$ & 43238 & $3.32^{*}(3.03-3.65)$ & $3.03^{*}(2.70-3.39)$ \\
\hline $51+$ & 24144 & $3.51^{*}(3.18-3.88)$ & $3.37^{*}(2.96-3.84)$ \\
\hline \multicolumn{4}{|l|}{ Area } \\
\hline Rural & 61421 & 1.00 (ref) & 1.00 (ref) \\
\hline Urban & 33235 & $2.93^{*}(2.77-3.11)$ & $1.79 *(1.64-1.95)$ \\
\hline \multicolumn{4}{|l|}{ Education } \\
\hline Illiterate & 7757 & 1.00 (ref) & 1.00 (ref) \\
\hline Literate & 17301 & $1.62^{\star}(1.41-1.87)$ & $1.07(0.89-1.30)$ \\
\hline Primary school & 24189 & $1.53^{*}(1.33-1.75)$ & $0.89(0.74-1.07)$ \\
\hline Secondary school & 26159 & $1.44^{*}(1.25-1.65)$ & $0.70^{*}(0.58-0.84)$ \\
\hline High school & 10145 & $1.99^{*}(1.71-2.30)$ & $0.63^{*}(0.51-0.77)$ \\
\hline Above high school & 9067 & $2.74^{\star}(2.37-3.17)$ & $0.62^{*}(0.51-0.76)$ \\
\hline \multicolumn{4}{|l|}{ Current occupation } \\
\hline Manual labourer & 56932 & 1.00 (ref) & 1.00 (ref) \\
\hline White-collar worker & 22316 & $3.65^{\star}(3.42-3.89)$ & $1.95^{\star}(1.78-2.13)$ \\
\hline \multicolumn{4}{|l|}{ Food expenditure level } \\
\hline Level 1 & 16057 & 1.00 (ref) & 1.00 (ref) \\
\hline Level 2 & 16804 & $1.49^{*}(1.28-1.74)$ & $1.42^{*}(1.17-1.73)$ \\
\hline Level 3 & 18537 & $2.17^{*}(1.88-2.50)$ & $1.81^{*}(1.50-2.18)$ \\
\hline Level 4 & 20972 & $3.51 *(3.07-4.00)$ & $2.71 *(2.27-3.24)$ \\
\hline Level 5 & 22120 & $7.18^{\star}(6.33-8.16)$ & $4.96^{\star}(4.14-5.92)$ \\
\hline
\end{tabular}

VNHS 2001-02 -Vietnamese National Health Survey 2001-2002; OR - odds ratio; Cl - confidence interval; ref - reference category.

* Significant at $P<0.001$.

† Adjusted for all other variables in the table.

In low-income countries (per capita GNP less than \$US 745), membership in lower SES groups provides protection against obesity ${ }^{7}$. In countries such as Thailand ${ }^{8}$, China $^{9}$ and Morocco ${ }^{10}$ (GNP less than \$US 2500 per capita), higher rates of overweight were also observed among the more affluent groups.

However, between 1992 and 2002, the per capita GNP of Vietnam almost doubled from \$US 230 to \$US $430^{17,32}$. As the national income rose, higher rates of overweight began to be observed even among lower-income women. These observations are consistent with a report by Monteiro et al. that the shift towards a higher prevalence of overweight at lower SES occurs at an earlier stage of economic development for women than it does for men ${ }^{7}$.

Higher levels of food expenditures were associated with higher rates of overweight. For each level of food expenditure, women were more likely to be overweight than were men, and urban dwellers had higher rates than rural dwellers. As the prevalence rate of overweight rose with time and as a function of economic development, higher rates began to be observed among the middleincome groups. These observations are consistent with past reports that the shift towards more overweight at lower incomes occurs first for women, as opposed to men ${ }^{7,11,21}$.

Urbanisation is another index of economic development. As populations shift physically from rural to urban settings, they alter their dietary and physical activity patterns ${ }^{25,33,34}$. Parallel surveys conducted in Thailand, Malaysia, Taiwan and other countries have suggested that changes in diet composition and eating habits may be the underlying cause of overweight ${ }^{6,8,34,35}$. Nutrition transition in developing countries has been associated with increased overweight rates $^{8,11,20}$. However, published reports suggest that the Vietnamese diet changed little during the $1990 \mathrm{~s}^{16}$. Therefore a drop in physical activity levels may have been the primary cause of the increase in overweight. Lack of physical activity and sedentary lifestyles have been linked to overweight in both the developing and developed world $6,8,9,31$.

Evidence suggests that the co-morbidities associated with obesity affect Asian populations at a lower BMI than Caucasian populations ${ }^{36}$. Therefore the WHO Expert Consultation recommends that the definitions of overweight and obesity in Asian populations should be set lower, at BMI of 23.0 and $27.5 \mathrm{~kg} \mathrm{~m}^{-2}$, respectively ${ }^{36}$. However, the same group also recommends that each Asian country decides about these definitions based on evidence of increased co-morbidity risks within its population. In Vietnam evidence for a lower cut-off level has not been established, which led us to use the general international BMI cut-off level of $\geq 25 \mathrm{~kg} \mathrm{~m}^{-2}$ for the definition of overweight. Following this higher cut-off 
level resulted in a lower prevalence of overweight than if we had used $23.0 \mathrm{~kg} \mathrm{~m}^{-2}$ as the cut-off point. However, our results still successfully illustrated the picture of rising overweight prevalence in Vietnam over the last 10 years.

The dynamics of body weight increasing as a function of gender and SES in developing nations deserves further study. Gender inequalities may contribute to the higher prevalence of overweight in women ${ }^{8,9,24}$. Undernutrition and overweight can be present within a single family ${ }^{34}$, suggesting that allocation of family food resources may be an important factor. Qualitative studies conducted in Argentina suggest that low-income women worked longer hours than men, slept less, ate fewer meals, allocated nutritious foods to other family members, and consumed more sugar and bread $^{22}$. It is possible to view the rising rates of obesity among women as a large-scale problem in women's health.

The present study had several limitations when it comes to assessing body weight, diet and health. First, the sampling methods for the three surveys were not identical. Second, dietary intake records were not available. Measures of physical activity and incomes were not included in either survey. However, the picture that emerges is clear. In Vietnam, the prevalence of overweight is rising among women and men. Currently, higher rates are observed among the higher SES (occupation and income) groups. However, as economic development proceeds, higher rates of overweight are also being observed at lower levels of SES. As Vietnam develops, public health officials should prepare to deal with diseases of both under- and overnutrition. Obesity is no longer a disease of affluence; it is increasingly becoming a global problem affecting the poor.

\section{Acknowledgements}

Sources of funding: This research was supported by the Vietnam Public Health Fellowship Program of the Population Council and the National Institute of Nutrition of Vietnam.

Conflict of interest declaration: There were no known conflicts of interest for any of the authors involved in this research.

Authorship responsibilities: M.D.N. as principal investigator of this study had full access to all of the study data and takes responsibility for the integrity of the data and the accuracy of the data analyses; he formulated the research question, conducted the analysis and wrote the paper. A.D. provided guidance throughout the study and critical revision of the manuscript for intellectual content. S.A.A.B. provided methodological expertise and critical revision of the manuscript for intellectual content.

Acknowledgements: The authors wish to thank Anne Lund MPH, RD for her editorial assistance. Ms Lund gave her permission to be acknowledged.

\section{References}

1 Drewnowski A, Popkin BM. The nutrition transition: new trends in the global diet. Nutrition Reviews 1997; 55(2): 31-43.

2 World Health Organization (WHO). Diet, Nutrition, and the Prevention of Chronic Diseases. Technical Report Series No. 916. Geneva: WHO, 2003.

3 Monteiro CA, Conde WL, Popkin BM. Is obesity replacing or adding to undernutrition? Evidence from different social classes in Brazil. Public Health Nutrition 2002; 5(1A): 105-12.

4 Monteiro CA, Conde WL, Popkin BM. The burden of disease from undernutrition and overnutrition in countries undergoing rapid nutrition transition: a view from Brazil. American Journal of Public Health 2004; 94(3): 433-4.

5 World Health Organization (WHO). The World Health Report 2002 - Reducing Risks, Promoting Healthy Life. Geneva: WHO, 2002.

6 Popkin BM, Gordon-Larsen P. The nutrition transition: worldwide obesity dynamics and their determinants. International Journal of Obesity Related Metabolic Disorders 2004; 28(Suppl. 3): S2-S9.

7 Monteiro CA, Conde WL, Lu B, Popkin BM. Obesity and inequities in health in the developing world. International Journal of Obesity Related Metabolic Disorders 2004; 28(9): 1181-6.

8 Kosulwat V. The nutrition and health transition in Thailand. Public Health Nutrition 2002; 5(1A): 183-9.

$9 \mathrm{Xu} \mathrm{F}$, Yin XM, Zhang M, Leslie E, Ware R, Owen N. Family average income and body mass index above the healthy weight range among urban and rural residents in regional Mainland China. Public Health Nutrition 2005; 8(1): 47-51.

10 Benjelloun S. Nutrition transition in Morocco. Public Health Nutrition 2002; 5(1A): 135-40.

11 Mendez MA, Monteiro CA, Popkin BM. Overweight exceeds underweight among women in most developing countries. American Journal of Clinical Nutrition 2005; 81(3): 714-21.

12 Sobal J, Stunkard AJ. Socioeconomic status and obesity: a review of the literature. Psychology Bulletin 1989; 105(2): $260-75$.

13 Haughton D, Haughton J, Phone N. Living Standard During an Economic Boom: The Case of Vietnam. Hanoi: General Statistics Office, Statistics Publishing House, 2001.

14 General Statistics Office. Statistical Year Book 2002. Hanoi: Statistical Publishing House, 2003.

15 General Statistics Office. Vietnamese Living Standard Survey 1997/1998. Hanoi: Statistical Publishing House, 2000.

16 Khoi HH. General Nutrition Survey 2000. Hanoi: Medical Publishing House, 2003.

17 World Bank. World Bank Annual Report 2003. New York: World Bank, 2003.

18 General Statistics Office. Vietnamese Living Standard Survey 1992/1993. Hanoi: Statistical Publishing House, 1995.

19 Ministry of Health. Vietnamese National Health Survey 2001-2002. Hanoi: Health Publishing House, 2004.

20 Monteiro CA, Moura EC, Conde WL, Popkin BM. Socioeconomic status and obesity in adult populations of developing countries: a review. Bulletin of the World Health Organization 2004; 82(12): 940-6.

21 Amoah AG. Sociodemographic variations in obesity among Ghanaian adults. Public Health Nutrition 2003; 6(8): 751-7.

22 Pan American Health Organization (PAHO). Obesity and Poverty: A New Public Health Challenge. Scientific Publication No. 576. New York: PAHO, 2000.

23 Gordis L, ed. Measuring the occurrence of disease. In: Epidemiology, 2nd ed. Philadelphia, PA: WB Saunders Company, 2000; 31-62.

24 Sarlio-Lahteenkorva S, Lahelma E. The association of body mass index with social and economic disadvantage in 
women and men. International Journal of Epidemiology 1999; 28(3): 445-9.

25 Ismail MN, Chee SS, Nawawi H, Yusoff K, Lim TO, James WP. Obesity in Malaysia. Obesity Reviews 2002; 3(3): 203-8.

26 Maletnlema TN. A Tanzanian perspective on the nutrition transition and its implications for health. Public Health Nutrition 2002; 5(1A): 163-8.

27 Griffiths PL, Bentley ME. The nutrition transition is underway in India. Journal of Nutrition 2001; 131(10): 2692-700.

28 Monteiro CA, Conde WL, Popkin BM. Independent effects of income and education on the risk of obesity in the Brazilian adult population. Journal of Nutrition 2001; 131(3): 881S-6S.

29 Panagiotakos DB, Pitsavos C, Chrysohoou C, Risvas G, Kontogianni MD, Zampelas A, et al. Epidemiology of overweight and obesity in a Greek adult population: the ATTICA Study. Obesity Research 2004; 12(12): 1914-20.

30 Laaksonen M, Prattala R, Helasoja V, Uutela A, Lahelma E. Income and health behaviours. Evidence from monitoring surveys among Finnish adults. Journal of Epidemiology and Community Health 2003; 57(9): 711-7.

31 Galobardes B, Morabia A, Bernstein MS. The differential effect of education and occupation on body mass and overweight in a sample of working people of the general population. Annals of Epidemiology 2000; 10(8): 532-7.

32 Central Intelligence Agency (CIA). The World Fact Book. Washington, DC: CIA, 1992.

33 Torun B, Stein AD, Schroeder D, Grajeda R, Conlisk A, Rodriguez M, et al. Rural-to-urban migration and cardiovascular disease risk factors in young Guatemalan adults. International Journal of Epidemiology 2002; 31(1): 218-26.

34 Lin YC, Yen LL, Chen SY, Kao MD, Tzeng MS, Huang PC, et al. Prevalence of overweight and obesity and its associated factors: findings from National Nutrition and Health Survey in Taiwan, 1993-1996. Preventive Medicine 2003; 37(3): 233-41.

35 Noor MI. The nutrition and health transition in Malaysia Public Health Nutrition 2002; 5(1A): 191-5.

36 WHO Expert Consultation. Appropriate body mass index for Asian populations and its implications for policy and intervention strategies. Lancet 2004; 363 (9403): 157-63. 